\title{
ANÁLISIS BIOQUÍMICO DE DOS FRACCIONES CON ACCIÓN ANTICOAGULANTE DE LAS HOJAS DE Oenothera rosea "CHUPASANGRE"
}

\author{
Mirtha Yarlequéa*, Miguel Zaldívara, Pablo Bonilla ${ }^{\mathrm{b}}$, Armando Yarlequéc
}

\section{RESUMEN}

Tradicionalmente las hojas de Oenothera rosea "chupasangre" son usadas para reducir los hematomas, por lo que, esta investigación estuvo dirigida a la evaluación de los componentes capaces de retardar la coagulación sanguínea. Del extracto etanólico de O. rosea se separó por cromatografía de capa fina en celulosa, usando etanol: agua (1:5), dos fracciones F-2 y F-5, que luego fueron preincubadas por 10 minutos con trombina y el veneno de la serpiente Lachesis muta, rico en Enzima Semejante a Trombina (EST) y luego se midió la actividad coagulante sobre plasma humano citratado y fibrinógeno bovino (Fb), así como el sustrato cromogénico BApNA. Los resultados mostraron que F-2 alargó el tiempo de coagulación sobre $\mathrm{Fb}$ en 58,58 \% y el F-5 en 67,78 \%, mientras que usando veneno los retardos fueron para F-2 10,67 \% y F-5 36,27 \%. Usando plasma, los valores fueron para F-2 34,14 \% y F-5 $70,59 \%$. Asimismo, empleando trombina la actividad amidolítica se redujo en F-2 48,48 $\%$ y F-5 67,32 \%, mientras que con la EST de L. muta la inhibición de F-2 50,20 \% y F-5 $69,10 \%$. Mediante estos ensayos in vitro se concluye que F-2 y F-5 podrían ser flavonoides anticoagulantes, con probable acción antitrombolítica.

Palabras clave: coagulación, flavonoides glicosilados, plasma, trombina, fibrinógeno, veneno.

\footnotetext{
a Laboratorio de Bioquímica y Principios Activos Naturales, Facultad de Medicina Hipólito Unanue, UNFV. Jr. Río Chepén 290, El Agustino. Lima, Perú. *E-mail: bioyarleque@gmail.com

b Laboratorio del Instituto de Investigación de Ciencias Farmacéuticas y Recursos Naturales "Juan de Dios Guevara” de la Facultad de Farmacia y Bioquímica, UNMSM. Jr. Puno N¹002. Lima, Perú.

c Laboratorio de Biología Molecular, Facultad de Ciencias Biológicas, UNMSM. Ciudad Universitaria - Cercado de Lima. Lima, Perú.
} 


\title{
BIOCHEMICAL ANALYSIS OF TWO FRACTIONS WITH ANTICOAGULANT ACTION OF THE LEAVES OF Oenothera rosea "CHUPASANGRE"
}

\begin{abstract}
Traditionally the leaves of Oenothera rosea "chupasangre" are used to reduce the bruising in humans. Therefore, this research was focused at evaluating of the fractions capable of retarding blood clotting. From the ethanolic extract of $\mathrm{O}$. rosea separated by thin layer chromatography on cellulose using ethanol: water (1: 5), F-2 and F-5, wich were preincubated for 10 minutes with thrombin and the venom of the Lachesis muta snake rich in EST (Thrombin-like enzyme) and then coagulant activity was measured on citrated human plasma and bovine fibrinogen, as well as the BApNA chromogenic substrate. The results showed that F-2 lengthened the clotting time over $\mathrm{Fb} 58,58 \%$ and F-5 67,78 \%, while using poison the delays were for F-2 $10,67 \%$ and F-5 36,27 \%. Using plasma, the values were for F-2 34,14\% and F-5 70,59 $\%$. Likewise, by using thrombin the amidolytic activity was reduced by F-2 48,48\% and F-5 67,32 \% while with the EST of L. muta the inhibition of F-2 50,20\% and F-5 69, 10\%. These in vitro tests conclude that F-2 and F-5 will be anticoagulant flavonoids with probable antithrombolytic action.
\end{abstract}

Key words: coagulation, glycosylated flavonoids, plasma, thrombin, fibrinogen, venom.

\section{INTRODUCCIÓN}

Uno de los problemas de salud de mayor importancia para el ser humano está relacionado con la obstrucción parcial o total del sistema circulatorio por aparición de trombos (trombosis). Esto se debe a la formación inusitada de coágulos de fibrina, a partir de fibrinógeno circulante, al activarse la cascada de coagulación. En este sentido, la exploración de diferentes componentes, especialmente de origen vegetal, es una labor continua ${ }^{1}$.

La especie Oenothera rosea Aiton, es una planta herbácea que se encuentra distribuida desde el suroeste de Estados Unidos, México hasta Argentina, pasando por Perú y Bolivia. Esta planta crece desde los 600 a 3900 m.s.n.m. y es conocida popularmente como "chupasangre", "sanguinaria", "hierba del golpe" y "yawar socco", ya que se utiliza tradicionalmente para resolver los hematomas o como cicatrizante, antiinflamatorio y para atender problemas gastrointestinales $^{2,3,4}$.

Algunos de los compuestos fenólicos presentes en las hojas de $O$. rosea han sido ensayados en sus efectos antiinflamatorios, cicatrizantes, antioxidantes, antiagregantes plaquetarios y más recientemente en su acción anticoagulante; sin embargo, no han sido reportados 
los compuestos responsables de dichos efectos ${ }^{4,5,6}$. En el año 2007, se ensayó la actividad anticoagulante del extracto etanólico/acuoso de $O$. rosea, "chupasangre", sobre el plasma humano citratado y en los últimos años se han realizado investigaciones sobre algunas de las fracciones acuosas separadas, evaluando su capacidad anticoagulante ${ }^{3}$.

En el año 2015, aislaron flavonoides del extracto metanólico y acuoso de Lancularia racemosa mostrando su efecto inhibidor sobre la trombina, además, se reportó que la quercetina y sus derivados glicosilados, tienen la capacidad de interactuar a nivel del centro activo de la trombina por bloqueo a nivel del aminoácido serina ${ }^{7}$. Asimismo, los flavonoides quercetina y silibina inhiben el factor X activado de la coagulación (Xa), a nivel de la Ser 195, reduciendo también la actividad amidolítica sobre el sustrato cromogénico BApNA ${ }^{1,8}$.

Recientemente, han reportado ensayos con 42 flavonoides para evaluar el efecto sobre la trombina, utilizando el sustrato cromogénico S-2238; sus resultados indican que algunos flavonoides mostraron fuerte efecto inhibitorio, IC50, con valores desde 56,50 $\mu \mathrm{M}$ a 99,70 $\mu \mathrm{M}$, estos son miricetina, scutellareína, isorhamnetina, miricitrina, baicalina, apigenina e hidroxigenkwanina 9 .

Por tanto, el objetivo de esta investigación fue evaluar el efecto anticoagulante de dos fracciones aisladas de O. rosea, usando como sustratos el Plasma Humano Citratado (PHC) y Fibrinógeno de Bovino (Fb), con el fin de contribuir a los esfuerzos científicos en la búsqueda de nuevas herramientas moleculares para contrarrestar las alteraciones cardiovasculares que afectan al ser humano ${ }^{7,8,9}$.

\section{PARTE EXPERIMENTAL}

\section{Muestras de Oenothera rosea}

Las muestras de Oenothera rosea Aiton fueron recolectadas en el distrito de Matucana, provincia de Huarochirí departamento de Lima, a 2378 m.s.n.m., en el periodo de octubre 2015 a febrero 2016. La planta completa fue colocada en una prensa para lograr su herborización y posterior identificación taxonómica en el Museo de Historia Natural UNMSM.

Se realizó la separación de las hojas, las cuales fueron colocadas en un lugar fresco y ventilado para que se sequen completamente para luego ser pulverizadas ( $300 \mathrm{~g}$ ) y colocadas en un frasco oscuro agregándole etanol de 960 (1 L) y se guardó en un lugar oscuro para su maceración por 7 días. Luego, el extracto fue filtrado en un matraz, utilizando papel Whatman No 4. Posteriormente se realizó la evaporación del solvente utilizando una estufa a $40{ }^{\circ} \mathrm{C}$, hasta su secado total. Para realizar las pruebas se pesaron cantidades variables del extracto seco, haciendo disoluciones con agua destilada. La parte soluble en agua se filtró con papel Whatman No1 y se evaporó en una estufa a $40{ }^{\circ} \mathrm{C}$, obteniéndose la fase acuosa (Fa) con la que se trabajó. 


\section{Veneno de serpiente}

El veneno liofilizado de la serpiente Lachesis muta fue proporcionado por el Laboratorio de Biología Molecular de la Facultad de Ciencias Biológicas de la UNMSM, a partir de especímenes mantenidas en cautiverio en el Serpentario "Oswaldo Meneses" del Museo de Historia Natural de esa institución. Se consideró que $1 \mathrm{mg} / \mathrm{mL}$ de veneno liofilizado de L. muta contiene $1,62 \mathrm{mg} / \mathrm{mL}$ de proteína, leído a $280 \mathrm{~nm}^{10}$.

\section{Marcha fitoquímica}

Se utilizó el extracto etanólico seco de hojas de $O$. rosea para obtener la fase acuosa (Fa) y realizar las reacciones cualitativas que permitieron evaluar la presencia de compuestos fenólicos, flavonoides, taninos saponinas y carbohidratos; por medio de reacciones de color, de precipitación y formación de espuma ${ }^{11}$.

\section{Cromatografía en capa fina}

Se realizó la cromatografía en capa fina, usando como fase estacionaria cromatofolios de celulosa y como fase móvil etanol: agua (1:5). Se realizó la siembra con una solución de 500 $\mathrm{mg} / \mathrm{mL}$ de la $\mathrm{Fa}$ utilizando capilares nuevos. Los reveladores utilizados fueron: tricloruro férrico al $1 \%$ y luz UV $365 \mathrm{~nm}$. El número de las fracciones obtenidas mediante este método fueron siete que se identificaron cualitativamente por fluorescencia. Las fracciones F-2 y F-5 fueron seleccionadas para los ensayos de la actividad anticoagulante, pues fueron capaces de retardar el tiempo de coagulación del plasma humano citratado.

\section{Cuantificación de flavonoides}

Los flavonoides totales fueron determinados por el método desarrollado por Zhishen et al. Se preparó un tubo que contenía $0,250 \mathrm{~mL}$ de la muestra que fue mezclada con $1 \mathrm{~mL}$ de agua destilada, se añadió $0,075 \mathrm{~mL}$ de $\mathrm{NaNO}_{2}$ y se dejó reposar por 5 minutos, luego se agregó $0,075 \mathrm{~mL}$ de $\mathrm{AlCl} 3$ al $10 \%$ y $0,5 \mathrm{~mL}$ de $\mathrm{NaOH} 1 \mathrm{M}^{12}$. La mezcla fue centrifugada a 3500 r.p.m. durante 5 minuto. Las absorbancias fueron medidas en un espectrofotómetro UV-Vis Génesis 10 a $510 \mathrm{~nm}$. Se preparó la curva de calibración utilizando Rutina como flavonoide estándar, a concentraciones $10 \mathrm{ug}$ a $100 \mathrm{ug} / \mathrm{mL}$.

\section{Actividad enzimática: Actividad coagulante}

Se realizó utilizando como sustratos plasma humano citratado y fibrinógeno bovino Sigma Chem. (5 mg/mL), y como enzimas la trombina bovina liofilizada ( $\mathrm{Tb}$ ) de la marca Sigma Aldrich y la EST presente en el veneno de L.muta. Se preparó la Tb a una concentración de $1 \mathrm{U} / \mathrm{mL}(0,020 \mathrm{mg} / \mathrm{mL})$, en solución de cloruro de sodio $0,85 \%$ y el veneno de serpiente fue preparado a una concentración inicial de $1 \mathrm{mg} / \mathrm{mL}^{10}$.

El plasma humano se obtuvo de donantes voluntarios de 20 a 30 años que no presentaban problemas hematológicos. Se extrajo $9 \mathrm{~mL}$ de sangre venosa y mezcló con $1 \mathrm{~mL}$ de citrato de sodio 3,8 \% (9:1), se centrifugó a $3500 \mathrm{rpm}$ durante 10 minutos para separar el plasma del paquete globular. El fibrinógeno bovino comercial fue preparado a una concentración de 5 $\mathrm{mg} / \mathrm{mL}$ en buffer Tris $\mathrm{HCl} 0,05 \mathrm{M} \mathrm{pH} 7,4$ a $37^{\circ} \mathrm{C}$. 
Para medir la actividad coagulante se preincubó $0,2 \mathrm{~mL}$ del sustrato y $0,1 \mathrm{~mL}$ de Buffer Tris a $37^{\circ} \mathrm{C}$, adicionándose luego $0,1 \mathrm{~mL}$ de veneno o trombina comercial. Con la ayuda de un cronómetro se midió el tiempo de coagulación en segundos. Para la medición de la actividad específica, se calculó las inversas del tiempo de coagulación y se dividió entre los mg de proteína utilizada.

En la determinación el efecto anticoagulante de las fracciones de $O$. rosea, se hicieron pre incubados de $500 \mathrm{uL}$, mezclando volúmenes iguales de veneno o trombina con las Fa, F-2 y $\mathrm{F}-5$, en tubos independientes, a los que se llevó a $37^{\circ} \mathrm{C}$ x 10 minutos; en todos los casos se empleó el doble de la concentración para las enzimas y para las fracciones. Luego, $100 \mathrm{uL}$ de cada preincubado fueron adicionados a las mezclas de reacción que contenían plasma o fibrinógeno, midiéndose el tiempo de coagulación en segundos. Se utilizaron como controles los tiempos de coagulación de la trombina y del veneno, respectivamente ${ }^{13}$.

Los preincubados que se prepararon fueron los siguientes: $\mathrm{Fa}+$ veneno, $\mathrm{F}-2+$ veneno, F-5+veneno, Fa+ trombina, F-2 + trombina y F-5+ trombina.

El porcentaje de inhibición de la actividad coagulante se halló por la sustracción de 100 menos el \% de Actividad Específica Coagulante (AEC) de cada una de las muestras (100 - \% AEC).

\section{Actividad amidolítica}

Se determinó empleando el método de Erlanger et al., utilizando el sustrato cromogénico Benzoil-Arginil-p-nitroanilida (BApNA) de la marca Sigma Chem. Se midió la liberación de p-Nitroanilina por espectrofotometría. La mezcla de reacción contenía 1,5 mL de BApNA a una concentración de $9 \times 10^{-4} \mathrm{M}, 0,5 \mathrm{~mL}$ de buffer Tris- $\mathrm{HCl} 0,05 \mathrm{M} \mathrm{pH} \mathrm{8,1} \mathrm{y} 100 \mu \mathrm{L}$ de la muestra (veneno de serpiente o preincubados). Luego de 15 minutos de incubación a 37 o C la reacción se detuvo la reacción con $1 \mathrm{~mL}$ de ácido acético glacial al $60 \%$, tomándose la lectura en el espectrofotómetro a $405 \mathrm{~nm}$. La Actividad Específica Amidolítica (AEA) fue calculada por los moles de p-Nitroanilina liberados por minuto por miligramo de proteína $(\mathrm{U} / \mathrm{mg})^{14}$.

\section{RESULTADOS Y DISCUSIÓN}

\section{Separación de las fracciones F-2 y F-5 de $O$. rosea}

La marcha fitoquímica reveló que la fase acuosa obtenida, así como las fracciones F-2 y F-5 dieron resultados positivos para fenoles totales y flavonoides, tabla 1. Además, fueron evaluados taninos por su capacidad precipitante de proteínas, saponinas por su acción detergente y carbohidratos por su asociación con algunos flavonoides; los que podrían modificar las actividades de las fracciones sobre la Tb y EST. La cromatografía en capa fina (CCF) utilizando celulosa permitió aislar dos bandas cromatográficas, con coeficiente de retardo (Rf) de 0,18 para F-2 y 0,90 para F-5. El Rf para el estándar Rutina fue de 0,36, este es un flavonol glicosilado en la posición 3 con ramnoglucosil (ramnosa y glucosa) lo que indica 
que se trata de un compuesto polar. Pero, la F-2 mostró ser más polar por presentar un valor de Rf más pequeño. Estas diferencias de polaridad permitieron una apropiada separación de las fracciones utilizando etanol: agua (1:5) como fase móvil (tabla 1). Por otra parte, los rendimientos encontrados fueron de 30,12 \% y 45,18 \% para F-2 y F-5 respectivamente, es decir, que a partir de $1000 \mathrm{mg}$ de la fase acuosa obtuvimos 301,20 mg (F-2) y 451,80 mg (F-5).

Estudios sobre la inhibición de la trombina por extractos vegetales han demostrado que son los flavonoides y sus derivados glucosilados los responsables. Los resultados muestran que las fracciones F-2 y F-5 se tratarían de flavonoides, lo que concuerda con los trabajos publicados por varios investigadores ${ }^{1,7,8}$.

Tabla 1. Marcha fitoquímica y separación de las F-2 y F-5 de O. rosea.

\begin{tabular}{lcccc}
\hline \multicolumn{1}{c}{ Pruebas } & Fase acuosa & F-2 & F-5 & Rutina \\
\hline Fenoles totales: Cloruro & + & + & + & + \\
férrico & + & + & - & + \\
Flavonoides: Shinoda & + & - & - & - \\
Taninos: Gelatina & + & + & - & + \\
Carbohidratos: Molish & + & - & 0,90 & 0,36 \\
Saponinas: Afrosimétrico & NA & 0,18 & + & + \\
Rf & & + & & \\
\hline
\end{tabular}

Presencia: +, ausencia: -. Método: cromatografía en capa fina en celulosa. Fase móvil etanol: agua (1:5). Rf: coeficiente de reparto. Fracción 2: F-2. Fracción 5: F-5. Flavonoide Estándar: rutina. NA: no aplica

Se han encontrado algunos flavonoides obtenidos de plantas cuyas acciones antiinflamatorias, cicatrizantes, anticoagulantes y antioxidantes han sido demostradas ${ }^{3,4,5,9}$. En este camino, la exploración de plantas utilizadas tradicionalmente en nuestro país ha posibilitado la obtención de dos constituyentes en los extractos de $O$. rosea capaces de alterar la actividad enzimática de la Tb y la EST; debido que, existen evidencias previas y tradicionales de su acción antitrombótica en personas afectadas ${ }^{3}$.

\section{Actividad coagulante de la trombina y la inhibición por F-2 y F-5}

En las tablas 2 y 3 se muestran los resultados de la acción coagulante de la trombina sobre el fibrinógeno bovino y el efecto inhibitorio de las F-2, F-5 y de la Fa. Como puede observarse, la $\mathrm{Tb}$ produce coágulos a tiempos no proporcionales con su concentración. Por lo que, se ha estimado calcular la Actividad Específica Coagulante (AEC) utilizando la inversa del tiempo de coagulación entre mg de proteína total.

En la cascada de coagulación, la Tb tiene un rol fundamental que depende de la conversión del zimógeno protombina ( $68 \mathrm{kDA})$ a su forma activa $(32 \mathrm{kDA})$. En este proceso, la trombina ataca las cadenas $\mathrm{A} \alpha$ y $\mathrm{B} \beta$ del fibrinógeno liberando fibrinopéptidos $\mathrm{A}$ y $\mathrm{B}$, respectivamente, 
es así, que el monómero de fibrina resultante se convierte en polímero de fibrina insoluble, es decir en coágulo. Los coágulos estables (trombos) formados no se degradan rápidamente, si no se aplica un componente bioactivo específico como el que se está investigando. La trombina es una serina proteasa inhibida por el complejo endógeno heparina - antitrombina $\mathrm{C}$ y también por el reactivo fluoruro de fenilmetilsulfonilo (PMSF), el cual genera una reacción irreversible con la serina 195, constituyente del sitio activo de la enzima ${ }^{15}$.

Por otro lado, la preincubación de la Tb con la Fa, así como las F-2 y F-5 (tabla 3) señalan claramente que los tiempos de coagulación iniciales se alargan, de acuerdo con los porcentajes de inhibición indicados. Es interesante notar que F-5 tiene la mayor actividad anticoagulante (67,78 \% de inhibición), seguida de F-2 (58,58 \%) y Fa (57,40 \%).

Algunas investigaciones han mostrado que los flavonoides como las quercetinas (Quer), pueden actuar como inhibidores competitivos de la trombina debido a su acoplamiento estérico a la His 57, parte del centro activo de la enzima, dicho acoplamiento es más estable si el flavonoide está glicosilado como ocurre con la Quer-ramnosil y la Quer-arabinosa ${ }^{7}$. Por otra parte, utilizando técnicas de acoplamiento molecular han identificado flavonoides como potentes inhibidores de la trombina, estos son: miricetina, scutellareína, isorhamnetina, miricitrina, baicalina, apigenina e hidroxigenkwanina. Los investigadores indicaron, que los carbonos $(\mathrm{C})$ que tenían mayor importancia en la inhibición de la enzima fueron: $\mathrm{C} 2, \mathrm{C} 3$ y C4 del anillo C; los C5 y C7 del anillo A; los C3', C4' y C5' en el anillo B, además, los enlaces $\mathrm{C}=\mathrm{C}, \mathrm{C}=\mathrm{O}$ y los sustituyentes $\mathrm{O}$ - metoxilo y $\mathrm{O}$ - glicosilo, Wang et al. ${ }^{9}$.

Tabla 2. Acción coagulante de la trombina sobre fibrinógeno bovino.

\begin{tabular}{cc}
\hline $\begin{array}{c}\text { Trombina bovina } \\
\text { Unidades }\end{array}$ & $\begin{array}{c}\text { * Tiempo de coagulación } \\
\text { (s) }\end{array}$ \\
\hline 4 & $18,67 \pm 1,53$ \\
$\mathbf{2}$ & $29,00 \pm 1,00$ \\
1 & $43,00 \pm 1,00$ \\
\hline lunidad $=0,02 \mathrm{mg} / \mathrm{mL}$ de trombina. \\
*Promedio $\pm \mathrm{DS}, \mathrm{n}=3$
\end{tabular}


Tabla 3. Inhibición de la actividad coagulante de la trombina por las F-2 y F-5 de $O$. rosea

\begin{tabular}{lcccc}
\hline \multicolumn{1}{c}{ Muestras } & $\begin{array}{c}\text { Tiempo de } \\
\text { Coagulación } \\
(\mathrm{s})\end{array}$ & $\begin{array}{c}* \text { AEC } \\
\times 10^{-3}\end{array}$ & \% AEC & $\begin{array}{c}\text { \% de } \\
\text { Inhibición }\end{array}$ \\
\hline $\begin{array}{l}\text { Control: } \\
\text { Trombina 0,02 }\end{array}$ & 29 & $6,896 \pm 0,60$ & 100 & -- \\
mg/mL & & & & \\
Fase acuosa + & 68 & $2,941 \pm 0,40$ & 42,60 & 57,40 \\
trombina & 70 & $2,857 \pm 0,50$ & 41,42 & 58,58 \\
F-2 + trombina & 90 & $2,222 \pm 0,60$ & 32,22 & 67,78 \\
F-5+ trombina & & & & \\
\hline
\end{tabular}

*Promedio \pm DS, $\mathrm{n}=3$. Enzima: Trombina $(1$ Unidad $)=0,02 \mathrm{mg} / \mathrm{mL}$.

Sustrato: Fibrinógeno bovino. F-2: Fracción - 2. F-5: Fracción-5.

AEC: Actividad Especifica Coagulante

Inhibición de actividad coagulante de la Enzima Similar a Trombina del veneno de la serpiente $L$. muta por la F-2 y F-5 de $O$. rose

La tabla 4 muestra los tiempos de prolongación de la coagulación, así como, las reducciones de la AEC cuando se utiliza el veneno de L. muta que contiene altas concentraciones de EST. En esta se aprecia la mayor actividad anticoagulante de F-5 en relación con F-2. Sin embargo, la actividad anticoagulante más elevada la presenta la fase acuosa, es decir del extracto acuoso total, que tiene un valor mayor que los encontrados en las fracciones. En la purificación de muchos componentes bioactivos, especialmente de origen vegetal, se observa la reducción de la actividad cuando ellos están separados, es decir, al parecer habría un sinergismo. Los componentes con una acción biológica definida cuando se encuentran en extracto total tienen mayor actividad que cuando se les separa.

En esta investigación se logró aislar dos fracciones (F-2 y F-5) capaces de prolongar el tiempo de la coagulación, al inhibir a la Tb y a la EST del veneno de L. muta. Sin embargo, el estudio debe continuar ya que estamos interesados en conocer la estructura química de estas fracciones, por la importancia y significado que tendría contar con fitoquímicos anticoagulantes que podrían ser utilizados en patologías trombóticas. 
Tabla 4. Inhibición de la actividad coagulante de EST de L. muta por las F-2 y F-5 de $O$. rosea sobre de fibrinógeno bovino y el plasma humano citratado

\begin{tabular}{|c|c|c|c|c|c|}
\hline Muestras & $\begin{array}{l}\text { Flavonoide } \\
\text { (ug) }\end{array}$ & $\begin{array}{c}* \mathrm{AEC} \\
\times 10^{-3} \\
\mathrm{Fb}\end{array}$ & $\begin{array}{c}\% \text { de } \\
\text { Inhibición }\end{array}$ & $\begin{array}{l}\text { *AEC } \\
\times 10^{-3} \\
\mathrm{PHC}\end{array}$ & $\begin{array}{c}\% \text { de } \\
\text { Inhibición }\end{array}$ \\
\hline $\begin{array}{l}\text { Control: } L \text {. } \\
\text { muta } 0,036 \\
\mathrm{mg} / \mathrm{mL}\end{array}$ & & $193 \pm 0,70$ & --- & $76,04 \pm 0,90$ & -- \\
\hline $\begin{array}{l}\text { Fase acuosa } \\
+ \text { veneno }\end{array}$ & 600 & $19,15 \pm 0,80$ & 90,08 & $28,04 \pm 0,70$ & 63,58 \\
\hline $\mathrm{F}-2$ +veneno & 24 & $172,41 \pm 0,70$ & 10,67 & $50,70 \pm 0,70$ & 34,14 \\
\hline F-5+ veneno & 24 & $123,00 \pm 0,60$ & 36,27 & $22,56 \pm 0,60$ & 70,69 \\
\hline
\end{tabular}

La actividad coagulante que presenta el veneno de $L$. muta es una de las más potentes en la familia de las serpientes viperidae (900 unidades NIH de Tb/mg), solo superada por su homóloga la "víbora de malasia" Calloselasma rhodostoma (1200 NIH Tb/mg); pero además, los coágulos de fibrina formados por estas proteínas son muy semejantes a los formados por la $\mathrm{Tb}$; esto es, debido a que hay un ataque simultáneo o sucesivo a las cadenas $\mathrm{A} \alpha$ y B $\beta$ del fibrinógeno para originar el monómero de fibrina. La mayoría de las serpientes de esta familia, se caracterizan por formar coágulos inestables debido a que el veneno solo ataca a una de las 2 cadenas A $\alpha$ o B $\beta$. Por otra parte, es necesario considerar que la Tb y EST tienen sus centros activos semejantes con la triada catalítica: His57, Asp 102 y Ser 195; lo que motivó su utilización en esta investigación. Adicionalmente, es necesario indicar que la EST no es inhibida por heparina ni tampoco se origina de un zimógeno (protombina) como es el caso de la $\mathrm{Tb}^{15}$.

Nótese también en las tablas 3 y 4 , que los \% de inhibición registrados para Tb y EST sobre el fibrinógeno bovino es muy distante para cada una de las fracciones 58,58 \% y 10,67 \% para F2, así como, 67,78 y $36,27 \%$ para F-5.

Asimismo, la tabla 4 registra los valores de inhibición obtenidos con F-2 y F-5 al utilizar plasma humano citratado, los valores encontrados fueron mayores (F-2 34,14 \% y F-5 70,69 \%) a los obtenidos con fibrinógeno como sustrato (F-2 10,67 \% y F-5 36,27 \%). Por otro lado, los valores de actividad amidolítica de EST usando BApNA como sustrato muestran inhibiciones de 50,20 \% y 69,10 \% con F-2 y F-5, respectivamente; mientras que, con la trombina los valores de inhibiciones encontrados fueron de $48,48 \%$ para F-2 y $67,32 \%$ para la F-5. 
Es conocido que, la $\mathrm{Tb}$ y la EST atacan al sustrato cromogénico BApNA al reconocer a la Arg como el aminoácido sobre el que actúan en las cadenas del fibrinógeno, liberando en este caso p-nitroanilina de color amarillo (tabla 5).

Un estudio acerca de la inhibición del Factor Xa utilizando análisis bioinformático reveló que los flavonoides procianidina B2, la cianidina, la quercetina y la silibina se unen a la Ser 195 del sitio activo, a través de sus dos grupos $\mathrm{OH}$ del flavonoide impidiendo la reacción normal con la $\mathrm{Arg}^{8}$. Estos resultados concuerdan con los reportados para los flavonoides miricetina, scutellareína, isorhamnetina, baicalina e hidroxigenkwanina, que indican la interacción entre los flavonoides con la Ser 195 inhibiendo de esta manera a la trombina ${ }^{9}$. La serina en la $\mathrm{Tb}$ como en la EST ocupa la misma posición, como aminoácido central, en el sitio activo.

Tabla 5. Inhibición de la actividad amidolítica de la Tb y EST de L. muta por las

F-2 y F-5 de $O$. rosea

\begin{tabular}{|c|c|c|c|c|}
\hline Muestras & $\begin{array}{l}\text { Flavonoide } \\
\text { (ug) }\end{array}$ & $\begin{array}{l}\text { *Actividad Específica } \\
\text { Amidolítica (AEA) } \\
\text { U/mg de proteína } \times 10^{-3}\end{array}$ & $\%$ de AEA & $\begin{array}{c}\text { \% Inhibición } \\
\text { de AEA }\end{array}$ \\
\hline $\begin{array}{l}\text { Trombina } \\
0,020 \mathrm{mg} / \mathrm{mL}\end{array}$ & & $24,95 \pm 0,40$ & 100 & 0 \\
\hline $\begin{array}{l}\text { Fase acuosa }+ \\
\text { trombina }\end{array}$ & 600 & $8,52 \pm 0,70$ & 34,15 & 65,85 \\
\hline $\mathrm{F}-2+$ trombina & 24 & $12,85 \pm 0,30$ & 51,52 & 48,48 \\
\hline F-5+ trombina & 24 & $8,15 \pm 0,40$ & 32,68 & 67,32 \\
\hline $\begin{array}{l}\text { L. muta } 0,036 \\
\mathrm{mg} / \mathrm{mL}\end{array}$ & & $22,91 \pm 0,70$ & 100 & 0 \\
\hline $\begin{array}{l}\text { Fase acuosa }+ \\
\text { veneno }\end{array}$ & 600 & $7,35 \pm 0,50$ & 32,08 & 67,85 \\
\hline $\mathrm{F}-2+$ veneno & 24 & $11,41 \pm 0,40$ & 49,80 & 50,20 \\
\hline F-5+ veneno & 24 & $7,08 \pm 0,50$ & 30,90 & 69,10 \\
\hline
\end{tabular}




\section{CONCLUSIONES}

En esta investigación se ha demostrado que en $O$. rosea existen por lo menos dos principios con actividad anticoagulante F-2 y F-5, los cuales fueron obtenidos mediante una cromatografía en capa fina de la fase acuosa.

F-5 mostró mayor acción anticoagulante con respecto a F-2, a juzgar por los valores de inhibición de trombina y enzima similar a trombina del veneno de L. muta.

Asimismo, la actividad amidolítica usando BApNA como sustrato, registró una fuerte inhibición cercana al $70 \%$, especialmente por parte de F-5.

Siendo el presente, un trabajo pionero en la búsqueda de componentes bioactivos capaces de inhibir la capacidad tóxica de los venenos de serpientes; esta investigación debe ampliarse determinando la estructura química de las fracciones aisladas, para estudiar sus potenciales farmacológicos en los tratamientos de los envenenamientos ofídicos.

\section{AGRADECIMIENTOS}

Esta investigación fue financiada con recursos determinados - CANON 2015; (Res. VRIN No 083-2015-UNFV).

A los docentes de la Cátedra de Bioquímica de la Facultad de Medicina Hipólito Unanue de la Universidad Nacional Federico Villarreal por las facilidades brindadas.

Al Bch. Dante Arturo Rueda por todo el apoyo brindado.

\section{REFERENCIAS BIBLIOGRÁFICAS}

1. Bijak M, Ponczek MB, Nowak P. Polyphenol compounds belonging to flavonoids inhibit activity of coagulation factor X. Int J Biol Macromol. 2014; 65: 129- 135.

2. Tello-Cerón G, Flores M, Gómez V. Uso de las plantas medicinales del distrito de Quero, Jauja, Región Junín, Perú. Ecol Apl. 2019; 18(1):11-20.

3. Yarlequé M, Rueda L, Yarlequé L. Efecto anticoagulante in vitro del extracto acuoso de Oenothera rosea Aiton" chupasangre". Póster presentado en: VI Jornadas San Fernandinas; 2007 sept 8 -10; UNMSM. Lima, Perú.

4. Díaz HV, Fuertes C, Whu D, Jurado B, Roque M, Arroyo J. Efecto antiagregante plaquetario in vivo y fibrinolítico in vitro del extracto etanólico de las hojas de Oenothera rosea Aiton (chupasangre). Rev Soc Qui Perú. 2011; 77(3):225-234.

5. Huari E, De la Cruz LA. Efecto terapéutico del extracto etanólico de las hojas de Oenothera rosea A. "chupasangre", en forma de crema farmacéutica. [Tesis para optar Título Profesional de Químico Farmacéutico]. Lima: Universidad Nacional Mayor de San Marcos; 2017. 
6. Villena NC, Arroyo J. Efecto antiinflamatorio del extracto hidroalcohólico de Oenothera rosea (yawar socco) en ratas con inducción a la inflamación aguda y crónica. Ciencia e Investigación. 2012; 15(1):15-19.

7. Rodrigues CF, Gaeta H, Belchor M, Ferreira M, Pinho MV, Toyama D, Toyama M. Evaluation of Potential Thrombin Inhibitors from the White Mangrove (Laguncularia racemosa (L.) C.F. Gaertn.). Mar Drugs. 2015; 13(7): 4505-4519.

8. Bijak M, Sut A, Kosiorek A, Saluk-Bijak J, Golanski J. Dual Anticoagulant/Antiplatelet Activity of Polyphenolic Grape Seeds Extract. Nutrients. 2019;11(1):93. doi: 10.3390/ nu11010093.

9. Wang X, Yang Z, Su F, Li J, Owusu E, Chang Y, et al. Study on Structure Activity Relationship of Natural Flavonoids against Thrombin by Molecular Docking Virtual Screening Combined with Activity Evaluation in vitro. Molecules. 2020; 25(2): 422. doi:10.3390/molecules25020422

10. Yarlequé M, Ortiz C, Morante Y, Yarlequé A. Estudio comparativo de algunas propiedades bioquímicas de venenos de serpientes de diferentes regiones del mundo. Rev Soc Quím Perú. 2012; 78(1): 27-36.

11. Lock O. Investigación fitoquímica: métodos en el estudio de productos naturales. Lima: Pontificia Universidad Católica del Perú; 2016.

12. Zhishen J, Mengcheng T, Jianming W. The determination of contents in mulberry and their scavengin effect on superoxide radicals. Food Chem. 1999; 64: 555-559.

13. Copley A. Studies of snake venom on the blood coagulation. I. The Thromboserpertin enzime in venoms. Thombos Res. 1973; I(2): 487-508.

14. Erlanger B, Kokowsky N, Cohen W. The preparation and properties of two new chromogenic substrates of trypsin. Arch Biochem Biophys. 1961; 95: 271-278.

15. Ruiz L, Vivas D, Lazo F, Seiferta W, Rodríguez E, Sandoval G, et al. Purificación y caracterización bioquímica de la enzima similar a trombina del veneno de la serpiente Bothrops brazili. Rev Soc Quím Perú. 2017; 83(4): 463-474. 